\title{
Cheating Death-by-PowerPoint: Effective Use of Visual Aids at Professional Conferences
}

\author{
Rob Salmond, University of Michigan \\ David T Smith, University of Sydney
}

\section{ABSTRACT We critique the typical use of visual aids at political science conferences and make suggestions about more effective ways to incorporate them into presentations. Our main suggestions are that political scientists should use fewer and simpler slides, and that those slides should contain visually rich information that illustrates a speaker's point with- out distracting the audience from his or her words.}

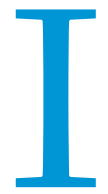

n April 2010, the New York Times published an exposé about PowerPoint use in the U.S. military (Bumiller 2010). The article was not complimentary. What emerged over its course was a culture of overreliance on visual aids, which were used almost as a substitute for oral briefings, coupled with user-unfriendly and sometimes farcically overcomplicated use of the medium. Junior officers were dismissively referred to as "PowerPoint Rangers" as a result of all the time they spent creating presentations, while the senior officers forced to endure those same presentations complained of not learning anything from them. One now infamous flowchart slide about the path to victory in Afghanistan was likened to a bowl of spaghetti.

Some business consulting firms and design professionals are now pushing back against this trend of "death-by-PowerPoint." These firms emphasize clean, simple visual aids that serve to reinforce, not replicate or replace, the oral points a speaker is making. Clutter, including wordy bullet points, most animation, and complex backgrounds, is frowned upon. Instead, muted and uniform slides serve as the backdrop to visually rich content that supports a speaker's oral point. "Design the content, not the page" is a common refrain. Perhaps the most influential proponent of this more minimalist, supporting-actor role for visual aids is the consulting firm McKinsey. Other helpful and less monolithic cases that have been made for this viewpoint can be found in The Visual Display of Quantitative Information (Tufte 2001), Presentation Zen (Reynolds 2008), and slide:ology (Duarte 2008).

Unfortunately for political scientists, the visual aids on show at our professional conferences have much in common with those

Rob Salmond is an assistant professor of political science at the University of Michigan and a faculty associate at the Center for Political Studies. His research interests are comparative political behavior and comparative democratic institutions. He can be reached at rsalmond@umich.edu.

David T Smith is a lecturer in American politics and foreign policy at the United States Studies Centre at the University of Sydney and also lectures in the department of government and international relations. His research interests are American and comparative political development and religion and politics. He can be reached at david.smith@ sydney.edu.au. used by the U.S. Army. Our presentations are increasingly made using software like PowerPoint, and they are jammed full of wordy bullet points, indecipherable equations, and unhelpful tables of empirical data that look like train schedules. We typically have too many slides for the time available, and the relationship between the slides and the talk is poorly thought out. In many cases, our visual aids stand as a barrier between the presenter and the audience, serving to distract and complicate rather than illustrate and clarify.

The nature of our enterprise is such that we likely cannot emulate the McKinsey-style mantras of the business consulting world. Three-words-per-bullet-and-three-bullets-per-slide is too stark for our purposes. But we can and should become less like the Army and its visual bowls of spaghetti. A move in this direction would be a mark of presenters' respect for their audiences.

In this article, we discuss and illustrate an effective slide presentation for a conference audience and contrast it with a number of less effective techniques that are commonly seen at professional meetings. This article is written as a complement to our other article on professional political science presentations, "Verbal Sticks and Rhetorical Stones: Improving Conference Presentations in Political Science," also printed in this issue of PS.

The subject of our hypothetical presentation is George Tsebelis' 2002 book Veto Players, selected because of its rich theoretical and empirical content and its relatively broad familiarity in political science. None of the slides we show, however, were produced by Professor Tsebelis. Instead, we have created these slides as illustrations of good, bad, and common practices at our large meetings.

In the following slide presentation, we have concentrated on content rather than slide design or animation. Put simply, complex slide design and slide transition (i.e., animation) are illadvised, because they distract the audience from the point a presenter is making and usually offer the audience nothing in return. For every series of animated bullet points that flies in at exactly the right moment, attracting mild transient admiration from the audience, there are 50 such series that fly in at the wrong moment or not at all, prompting presenters to waste everybody's 
time with sentences like: "Okay, so I said that, and also that, and that. Oh, here we are. Wait, it disappeared! How do I go back?"

\section{A BRIEF NOTE ON TIMING}

Based on our experience viewing political science presentations, in this article, we assume that presenters want to emphasize either their substantive theory or their empirical results, and that they want to spend around half their allotted time on this element of the presentation. Time estimates in the rest of this article flow from this presumption. In "Verbal Sticks and Rhetorical Stones," we discuss in more detail why this structure is a good one, and what presenters might do if their presentation's focus lies elsewhere (e.g., on a statistical method or data source).

\section{OPENING THE TALK}

The presenter's goal at the start of a conference presentation is to familiarize the audience with the goals of the paper, as well as the literature on which it draws. In a typical 15-minute presentation, a presenter has a maximum of four minutes to achieve both of these goals. By the end of the four minutes, the audience members should have decided: "This is potentially interesting. I will stay attentive through the rest of this talk." Securing the audience's attention is not an easy feat, as conference attendees have many competing demands on their time and energy. Even if people are physically present at a conference session, there is no guarantee that they are paying close, careful attention to all the presentations they attend. They need to be wooed.

Given the tight time frame, the number of slides that a presenter uses should be minimal at the start of a talk, and the audience's focus should be directed toward the speaker. One effective strategy is to tell the audience a story:

Some aspect of the political world is puzzling, and getting an answer is important. Some political scientists thought they had found the answer in earlier work. They thought the answer was X. But their work cannot fully explain the puzzle we care about, because of wrinkle Y. In this paper, I propose $\mathrm{Z}$ as an improvement on the earlier answers, getting us closer to solving this puzzle.

Telling this kind of story requires very little in the way of visual aids, mainly because any visual aids that would be relevant to this part of the talk are likely to be replicating the presenter's words rather than adding to them. A title slide, one slide on the existing literature, and one slide illustrating a major contribution is plenty. Some presenters are able to tell the story with even fewer visuals.

\section{Title Slides}

Title slides are more valuable than they might appear. These slides are often shown for about 10 seconds while the author agrees with the chair about the title of the paper, and they are then replaced, often by a "plan for the talk" slide. While longer format talks such as job talks or lectures do benefit from a slide that outlines the direction of the talk for the audience, a 15-minute presentation likely does not require a formal guide. Instead, presenters could consider telling their story while keeping the title slide on the screen longer. This strategy can assist the presenter, because the lack of a new slide helps audience members' focus stay on the individual and his or her story, and because anyone in the audience whose interest is sparked immediately or who comes in late has easy access to the talk's title and the presenter's name. Care should be taken to only include the most important information (talk title, presenter name, presenter affiliation) on the slide. The audience already knows that they are at the APSA conference in Washington, DC, and that the date is September 20oo. Nor does the audience need a full mailing address. Including unnecessary information is one of many problems that results from simply replicating a page of the written paper and placing it in a presentation-a disturbingly common practice, particularly for title slides and in empirical sections. Furthermore, pdf replications are almost impossible to read from more than six feet away, meaning that they are devoid of any usefulness to the audience.

\section{Slides on the Literature}

Slides on the literature should focus on substance and be sparse. The aim of the slide is to familiarize the audience with the structure of the presenter's take on the literature, not with the critique's detailed content. In this way, the slide acts as a map for the audience, helping them follow along with the verbal critique. The common practice of lifting complete sentences from the paper into the slides, which is especially prevalent in sections concerning literature review, is not helpful. This practice is illustrated in "less effective" slide 3 of figure 1 . Complete sentences do not allow viewers to see the review. Instead, they have to read it, which takes their attention away from the presenter. If a sentence is beautiful, then it may belong in the talk. But very few of our sentences are so beautiful as to be visually beautiful.

In our view, the common practice of listing various citations in these slides is also unhelpful. They cause clutter, making it harder for listeners to follow along with the presentation, and the audience generally gains nothing from their inclusion. If a member of the audience is already familiar with the literature under discussion, then he or she already knows the names of the touchstones, making their inclusion superfluous. If an audience member is not familiar with the literature, then including the names does not help him or her to follow the presenter's logic.

There are sometimes exceptions to this advice. If a presenter is delivering a paper entitled "The Con in Consociationalism: Why Arend Lijphart Cannot Predict the Present" or "Plus-a-Half? The Erroneous Dimensionality of Poole and Rosenthal," then it may be beneficial to spend more time familiarizing the audience with the single work under critique. However, most political science presentations are about entire classes of literature and political action, which mandates a stripped-down approach to the literature. A single literature review slide can outline a simple research area or question that the relevant literature covers, such as "veto players," "the democratic peace," or "Do campaigns matter?" This slide should include an extremely brief bullet point summarizing what the literature cumulatively says and a similarly brief talking point on where the literature currently falls short.

\section{Slides Previewing the Main Contribution}

These slides offer the presenters' first chance to suggest a onepoint summary of the talk to the audience. After the presentation is over, audience members should be able to easily recall: "This person said that the answer to puzzle A was B, for reason C." Formulating that sentence for the audience increases the likelihood of this kind of recall, because it is no longer dependent on audience members' individual initiative to think through and summarize the talk for themselves. This slide should therefore make two-and only two-points: What is the proposed answer to the puzzle? What is the dominant reason that this 
Figure 1

Slides for the Opening of a Talk

More effective

\section{Veto Players}

How Political Institutions Work

George Tsebelis, UCLA
(1)

2

How we think about political institutions

- Single determinative conditions:

- Separation of powers

- Electoral systems and party systems

- Bicameralism

- Question: How do these determinative conditions interact?

- Existing theories provide incomplete answers

3

Veto players: A metric for interaction

- Veto players: gatekeepers to political action

- They can decisively say "no"

- Advantages:

- A simple metric of complex change

- Flexible to institutional innovation

answer is preferable to others? This initial statement of the broad finding is an area in which replication of the paper's text or overcomplication of the proposed answer frequently harms presentations. Preview slides are not the place for nuance. Simplicity is emphasis.
Less effective

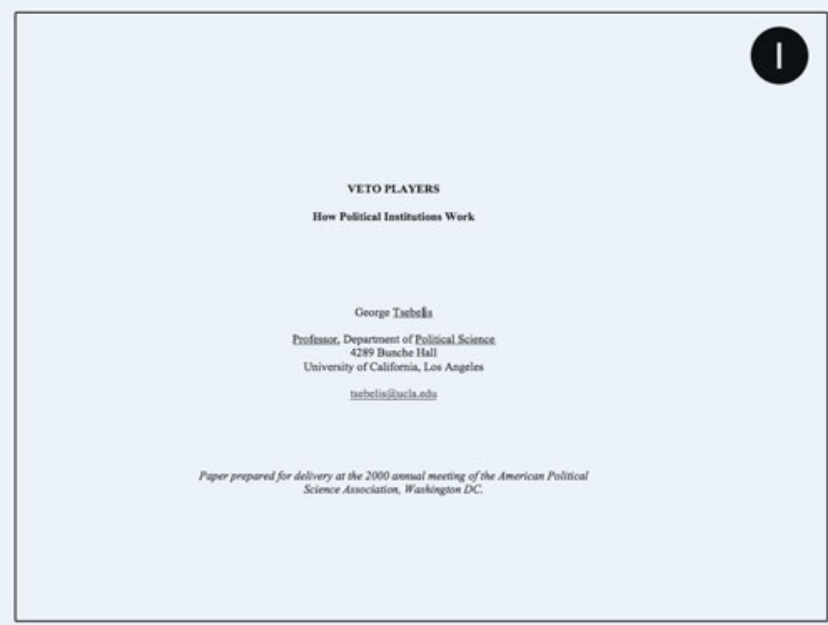

2

Plan for the talk

- What is a veto player?

- Previous literature related to veto players

- An illustration of how veto players affect policy making

- Two empirical tests:

- Veto players and the passage of important legislation

- Veto players and budgetary change

- Conclusions and discussion

\section{Literature review}

Most of the literature on political institutions uses a single criterion to identify the main characteristics of a polity.

- Presidentialism (Linz 1994, Horowitz 1994)

- Electoral systems (Cox 1997. Duverger 1954, Liphart 1984, 1999. Taagepera and Shugart 1989)

- Party systems (Duverger 1954, Sartori 1976)

- Cultural outlook (Almond and Verba 1963)

- The relationships among all those categories are underdeveloped. For example, how are we to compare the United States, a presidential bicameral regime with two weak parties, to Denmark a parliamentary unicameral regime with many strong parties?

\section{PRESENTING A THEORY}

In a 15 -minute presentation, the theoretical argument may take between two and eight minutes to explain, depending on whether the focus of the paper is theory or evidence. Visual aids can play an important role in this section of the talk, as they help the 
presenter illustrate a theoretical argument, often using flow charts or diagrams.

Most cutting-edge theoretical arguments in political science are complicated, given that the simple answers have already been proposed, tested, and built upon. These complicated arguments take authors months to create and weeks to write down. A reader usually does not fully absorb a nuanced, complex theory in one sitting. Understanding a theory in written form takes hours, especially if it is heavily reliant on formal modeling. Given all this complexity, it is virtually impossible to verbally explain a theory in all its glory in two to eight minutes to an audience that has not heard it before and cannot easily rewind to the parts they do not immediately understand. Many presenters are rightly proud of their theories and seek to achieve this improbable goal. When they do not accomplish it, however, they pay a heavy price, because their theoretical work is (often unjustly) dismissed by audience members as "confusing," "a mess," or "incomplete."

In a conference presentation, theoretical discussions should have two goals. First, the audience needs to become aware in very general terms about some predictions the theory makes and how it arrives at them. Second, the audience should come to broadly understand what makes this theory different and better than earlier theories on related subjects. We advise presenters to discard most or all of the technical information in their theory and concentrate on the theory's intuition and mechanism in their most rudimentary forms. Attempting to move an audience beyond this basic level of understanding in the time available is a fraught enterprise.

It is unreasonable, for example, to expect an audience to understand complex mathematical models of politics after one brief viewing of the formula. Even if the formula were physically readable from 30 feet away (which many are not), gaining this understanding is too difficult a cognitive challenge for the average conference participant, particularly when new concepts are involved or the model has more than one moving part.

Given that the audience will likely not follow a presentation of this type, presenters should normally avoid including complex equations in their slides. Many audience members will at least attempt to make sense of the equation, despite the small subscripts and large distance from the screen. This effort distracts them from the talk, and they will, in all likelihood, ultimately not be able to comprehend the equation by the time the presenter has moved on to the next slide. This failure leaves them both distracted and unclear about what just happened in the talk.

Some may feel that presenting these formulas does serve an important purpose-namely, to show that the presenter can back oral theoretical claims with rigorous technical analysis. If the rigorous technical analysis is presented with absolute clarity, it can indeed serve this purpose. But, as discussed previously, that clarity is exceptionally difficult to attain when presenting technical material in just a few minutes. A comment often heard at conferences is: "The authors were really teched-up, but I'm not sure what they were ultimately trying to say." That is not a compliment. A small number of our colleagues are able to be entirely clear in their presentation of very technical material, but for the rest of us, it is better to be clear than technical. If presenters are clear, then they may induce some audience members to read their written work, which is where technical competence and flair really shine.

Instead, diagrams and flow charts can help an audience follow along with a presentation without distracting or losing them. These pictorials are visually interesting in a way that equations are not.
Every game theoretic model has an extensive form or a $2 \times 2$ table, every agent-based model has a series of decision nodes, and every formal argument has a series of propositions and conditions.

In the Veto Players example, in the "more effective" slides 4 and 5 of figure 2, we present the intuition of the veto players theory using one relatively simple spatial diagram that shows how three veto players might think about policy in two dimensions. The presenter can talk the audience through how the theory operates and describe how it reaches its primary conclusion (i.e., more veto players or more distant veto players lead to more policy stability) using only this diagram and his or her arms, as if he or she were a weather presenter. In this way, the audience comes to understand something of the theory and is never distracted from the talk itself. By contrast, if a presenter tries to advance the veto players presentation to present every moving part in a second diagram, the probability of losing audience members increases dramatically. (As a thought experiment, look at the "less effective" slide 6 in figure 2 and attempt to complete the following paragraph in less than 30 seconds: "As you can see on the slide ...") Other errors in the "less effective" slides depicted in figure 2 include lifting of complete sentences from the text, trying to explain the minutiae of a theory in a few minutes, depicting overly complex diagrams, and superfluously reproducing the formula for a circle.

This last element is caricatured, but plenty of presentations at professional meetings show far more complex formulas to visually support discussions about equilibrium concepts and regression techniques in which the formula is equally as unnecessary and equally as distracting. For most panels, presenting formulas makes a presentation worse, not better.

As always, however, there are some exceptions to this advice. Refusing to show formulas while presenting papers on panels such as "Election Forensic Techniques Revealed" or "Bayesian Equilibrium Concepts Redux" is likely a mistake. In addition, some theoretical or empirical models are not often used in political science and may therefore need to be discussed in a talk when the presenter has used them in his or her argument. In these circumstances, it is imperative that presenters make sure their audience can actually see the formula being discussed-an unreadable formula is a waste of time, even if it is substantively appropriate. This may require showing only the most important or novel part of a formula rather than the whole thing.

\section{EMPIRICAL ANALYSES}

Depending on the focus of the work, an empirical analysis section of a conference presentation might run anywhere from two to eight minutes. As with the presentation of theories discussed previously, a presenter's empirical analyses will almost always need to be simplified to present them effectively in this timeframe. If a paper uses both a rich original data source and technically sophisticated analyses, then the presenter should concentrate on only one of those elements during the talk and present the other only in passing.

Presenters of empirical work should have either two or three goals in mind as they craft their talk and slides. Two elements that all empiricists need to address are: (1) what their analyses comprise, and (2) whether their analyses are broadly consistent with their expectations. A third element that only some presentersusually those whose focus is deeply empirical-will address is what makes their analyses better than earlier empirical work in the field. Any material that is irrelevant or only marginally relevant to these 


\section{More effective}
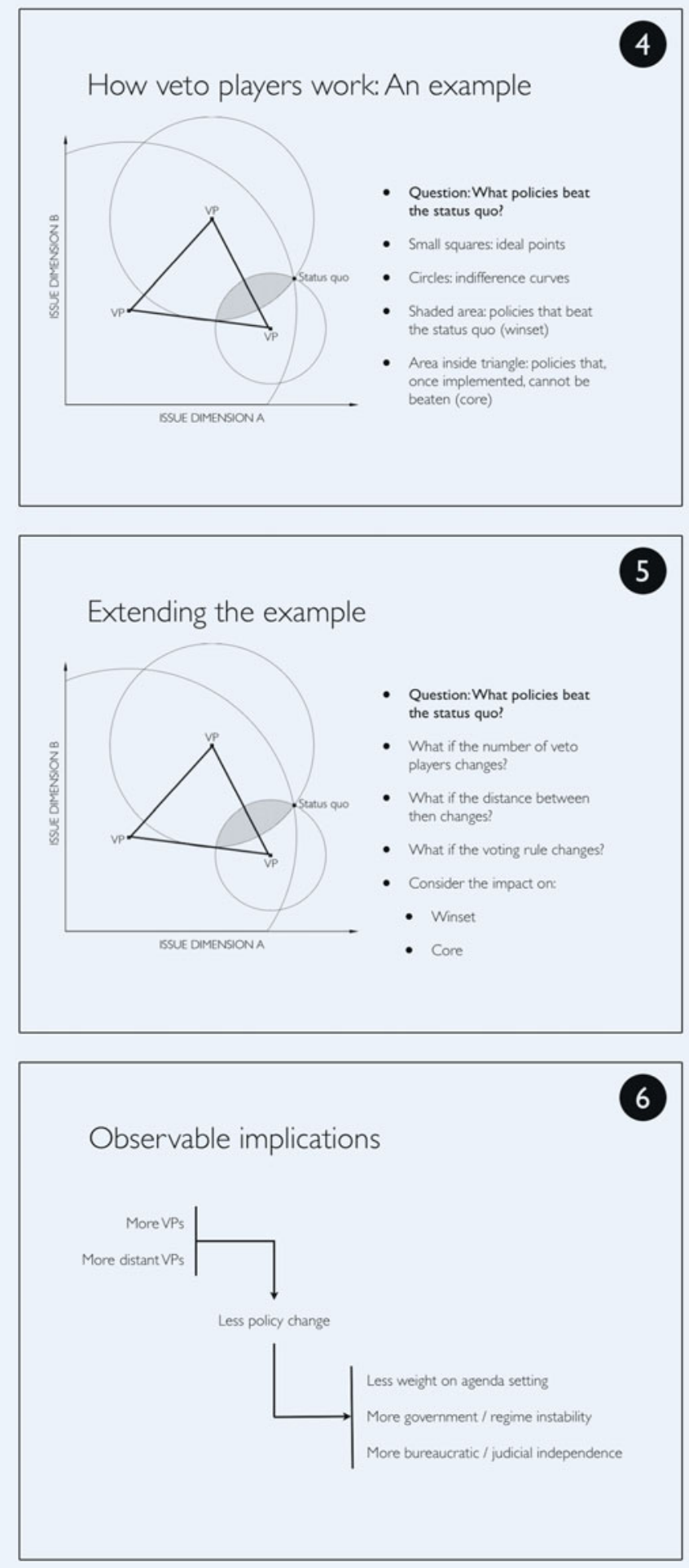

two or three questions needs to be discarded, lest the presenter find him or herself with only two minutes of remaining time in which to present 10 minutes of material.

For many presenters, a description of the structure of the analysis should take only one slide and one to two minutes. Most

\section{Less effective}

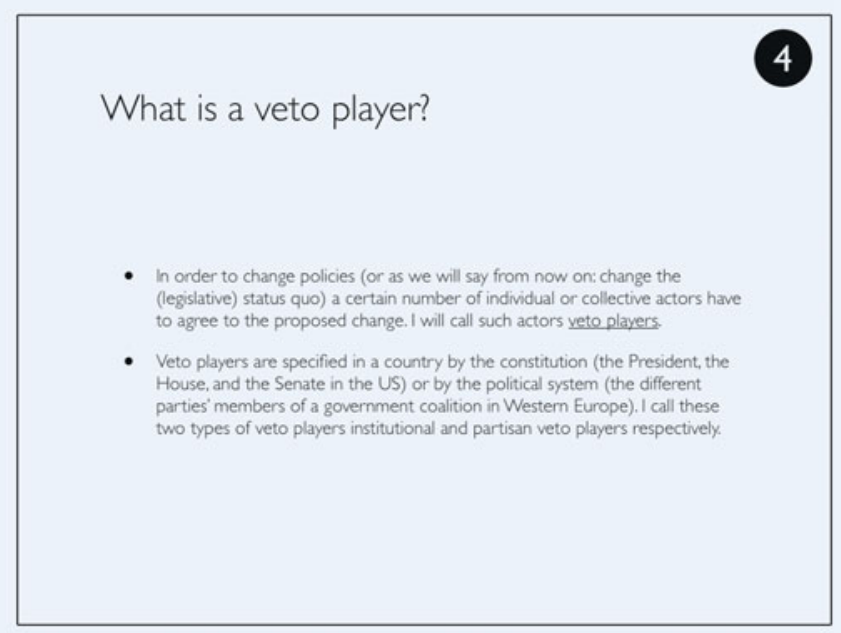

5

Veto players theory: Five simple rules

- NUMERICAL CRITERION:The addition of a new veto player increases policy stability (either by decreasing the size of the winset of the status quo, or by increasing the size of the unanimity core).

- ABSORPTION RULE: If a new veto player $D$ is added within the unanimity core of any set of previously existing veto players, $D$ has no effect on policy stability.

- QUASI-EQUIVALENCE RULE: For any set of existing veto players $S$ the necessary and sufficient condition for a new veto player $D$ not to affect the winset of any SQ is that $D$ is located in the unanimity core of $S$.

- IDEOLOGICAL DISTANCE RULE If Ai and Bi are two sets of veto players, and all $B i$ are included inside the unanimity core of the set $A i$, then the winset of $A_{i}$ is included in the winset of Bi for every possible status quo and vice versa.

- AGENDA SEITING RULEThe veto player who sets the agenda has a considerable advantage: he can consider the winset of the others as his constraint, and select from it the outcome he prefers.

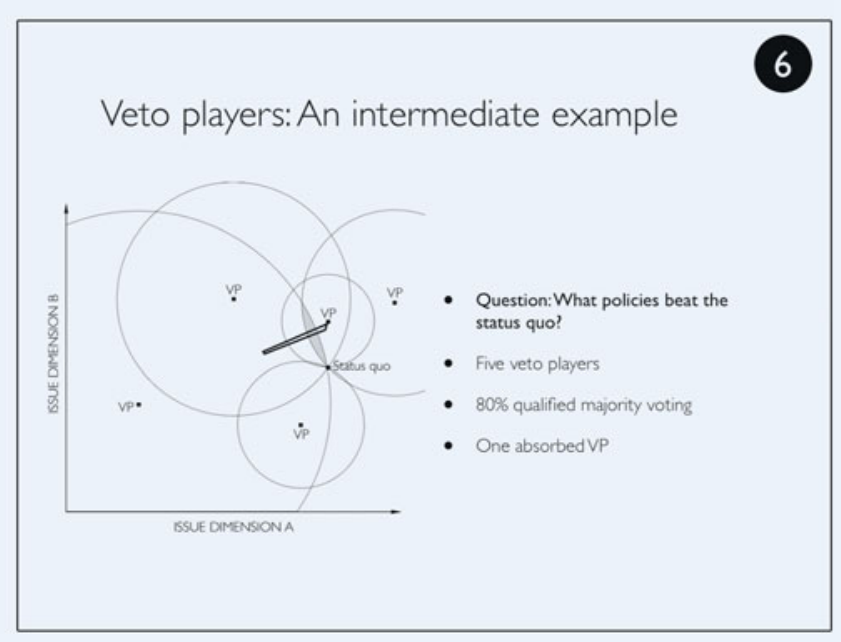

political science papers use data collected by somebody else, sometimes supplemented with one or two new variables, and analytical techniques that have been well established by others. An audience gains little from hearing about these data and techniques in detail, because the level of detail is unnecessary 
Figure 2 (Continued)

More effective

[This area very intentionally left blank]

\section{Less effective}

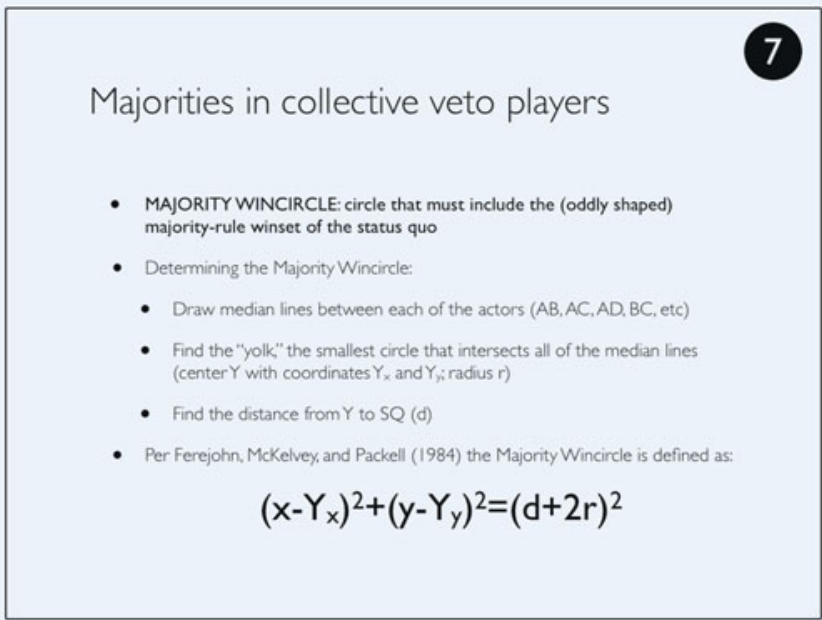

8

Majorities in collective veto players

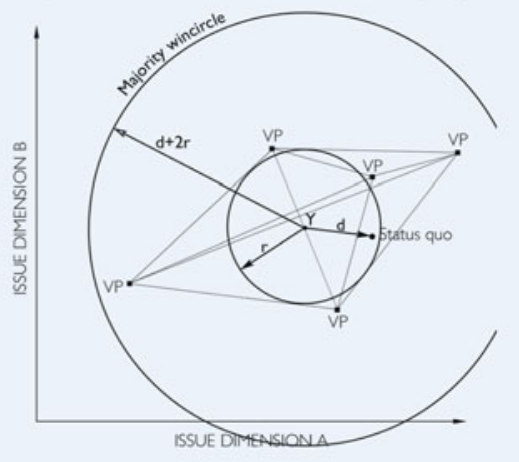

Hypotheses

\footnotetext{
HI. As the number of veto players rises, the amount of policy change falls

$\mathrm{H} 2$. As the distance between the veto players rises, the amount of policy change falls

H3. As policy change falls (that is, policy stability rises), agenda setting powers become less important

H4. As policy change falls (that is, policy stability rises). government / regime stability falls

H5. As policy change falls (that is, policy stability rises), bureaucratic and judicial independence rise
}

for audience members already familiar with the data and insufficient for unfamiliar audience members to build an adequate understanding. Instead, presenters should briefly note the data and techniques they are using, pausing to mention only those areas in which their use of the data or techniques is new or novel. A slide in this area need only consist of a few simple bullet points.

We do stress, however, that papers that do include either major new data collection or a significant analytical advance should emphasize these facets much more than we have recommended 
Figure 3

Empirical Section Slides

More effective
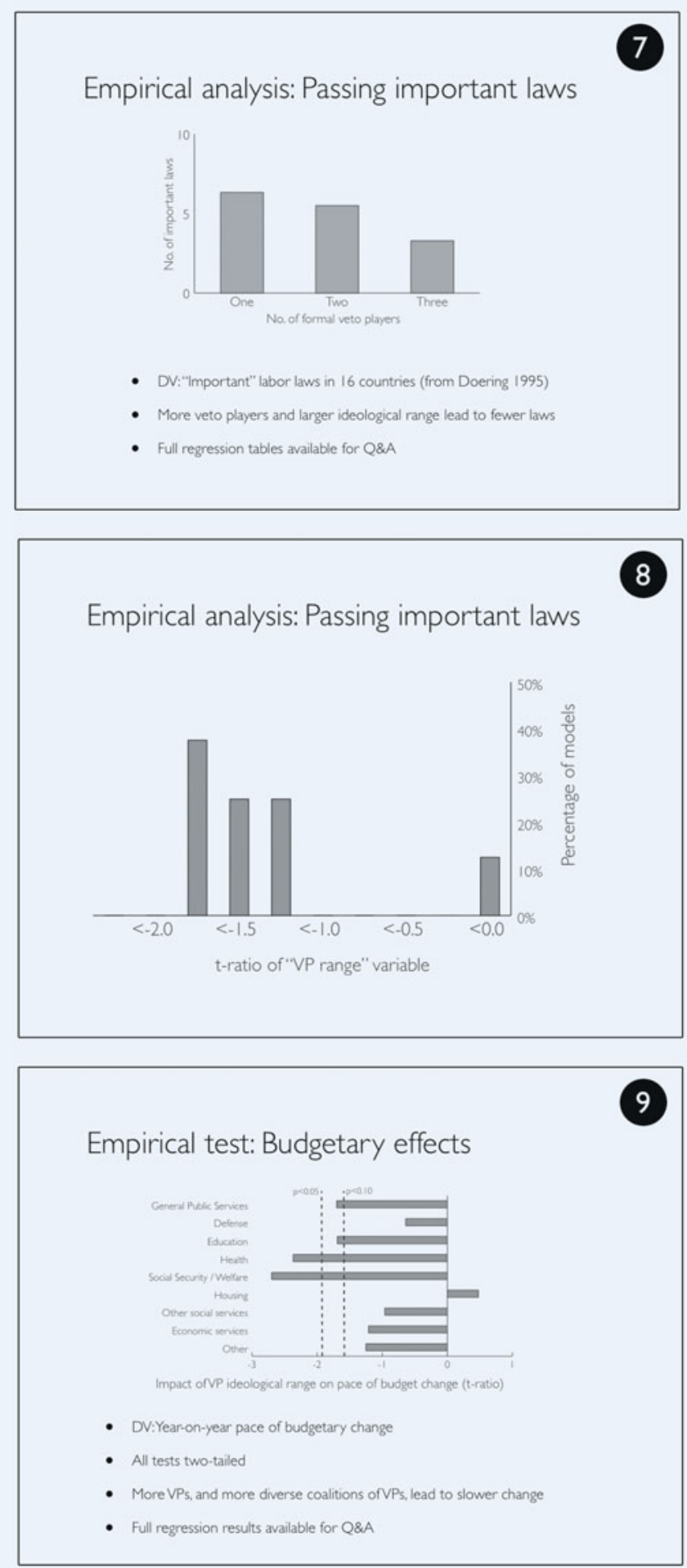

here. These presenters should remember that some other aspect of the paper will need to be glossed over as a result. When preparing this kind of presentation, presenters should be careful to make their presentation as broadly understandable and relevant as possible.

\section{Less effective}

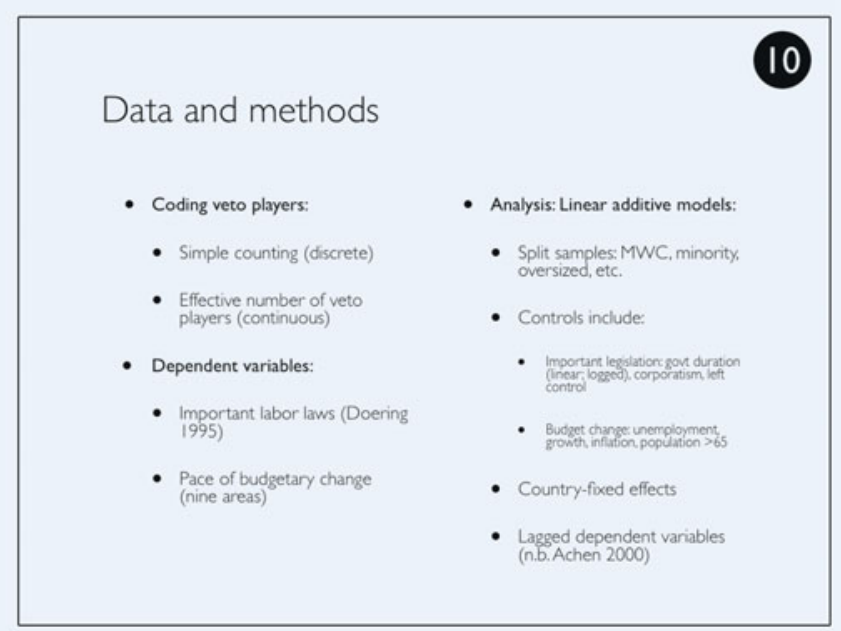

(11)

Veto players and passing important laws

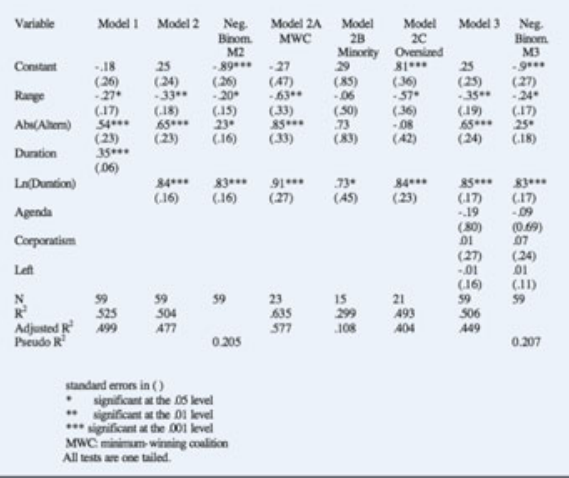

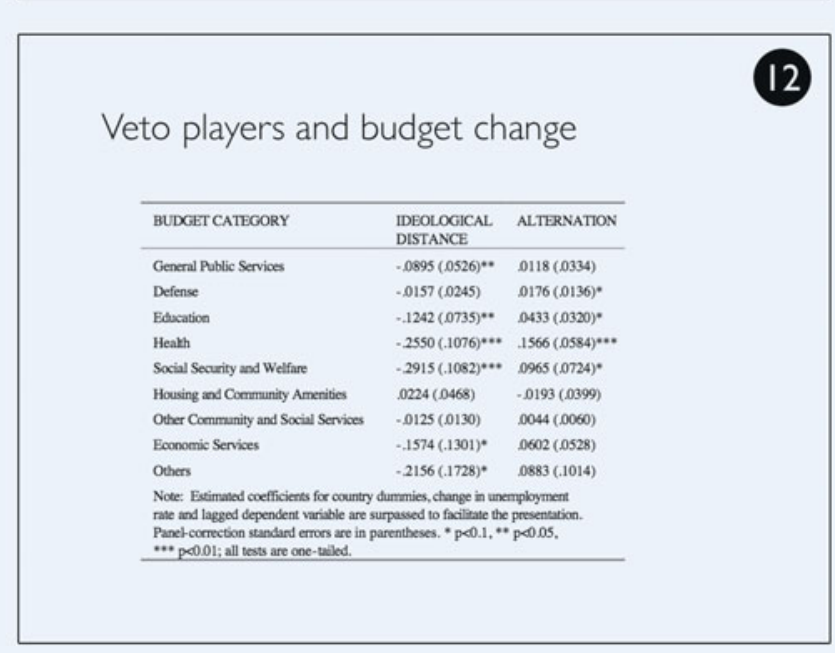

Current practices in empirical visual aids do not serve presenters well, as they often serve to confuse audience members and distract them from the point of the talk. One very common practice is to replicate on a slide a table of regression results drawn from the paper. This is unhelpful for three reasons: 
1. These slides are, almost without exception, unreadable beyond the first row, meaning that much of the audience has no way of following the "as you can see in the table" discussion of the results.

2. These slides normally invite or even require audience members to concentrate on the slide instead of the talk for an extended period in order to find the variables of interest and estimate their statistical significance by dividing coefficients by their standard errors or interpreting a regime of stars. This problem of misdirected focus becomes substantially worse when the presentation involves regression models including more than one variable of interest, such as interactive models, or more than one way of interpreting the variable of interest, such as sets of estimations with multiple dependent variables.

3. The slides often include large quantities of information that are only marginally relevant to the research question at hand. Presenting all the control variables from a survey-based regression, for example, does little to help explain whether the variable "South" affects the dependent variable, but does a lot to distract the audience from the presenter's point. There are plenty of ways to tell the audience why the analyses are trustworthy.

For these reasons, these slides should usually be avoided in presentations, but the presenter should make them available in case a question arises during the question and answer period. Where regression results on variables other than the main variable of interest are helpful to a substantive point, presenters should note the performance of their control variables or diagnostics in their oral presentation. Mentioning these control variables orally will also help audience members decide whether they trust the analysis.

Instead of depicting all of their models in their entirety, presenters should either show an excerpt from one or two regression models that include only variables of interest and key diagnostics or show elements of the regression results in graphical form. In the Veto Players example, in figure 3, "more effective" slides 7-9, we illustrate this second option using a number of different techniques, most commonly involving various plots of $t$-ratios. Raw scatterplots can also be very helpful, as can the graphical method for illustrating multiplicative regressions that Brambor, Clark, and Golder (2006) recommend. Readers might contrast the ease of interpreting the horizontal bar chart in figure 3 ("more effective" slide 9) with the ease of interpreting the table of regression results beside it ("less effective" slide 12). These slides depict the same data analyses, but the bar chart reveals the tenor of the results to a reader far faster than do the regression results, allowing audience members' attention to return to the speaker much more quickly. Edward Tufte's (2001) work on visualizing statistical information provides a multitude of helpful examples in this area.

\section{CLOSING REMARKS}

If a presenter has already established the presence of a puzzle in the political world, proposed an answer to the puzzle in a clear and straightforward manner, and shown evidence that this answer is correct, concluding should be easy. In a 15-minute presentation, the conclusion should take no more than three minutes, often less, and should require only one slide. The broad points that a speaker may want to make, each of which attracts one bullet point in a slide, are:
1. Repeat the main take-home point of the presentation. What, in the speaker's mind, should the audience have gathered from the presentation? Remember that the audience does not have the capacity to remember entire presentations, so this takehome message needs to have one or possibly two points.

2. Briefly recap the way in which the paper being presented arrives at its main conclusion. Remind the audience of the logic of the theory and the power of the evidence.

3. Address residual concerns. Is there a large remaining issue that hurts the credibility of the paper's findings? If so, it is better to own up during the presentation and spend the Q\&A discussing how to fix it than to stay quiet in the presentation and endure multiple questioners pointing out a problem that the presenter had already diagnosed.

4. Outline where future research can go from here. What does the presenter think is the next step in this research agenda? Presenters should move in a more expansive direction rather than simply calling for more research.

This final section is mainly about closing off the narrative of the talk. The closing remarks may not even need a slide at all, because the added value in this part of the presentation comes from the speaker's words. If the final slide from the previous section is complicated or very interesting, however, its continued presence could distract an audience from the presenter's wrap-up, which is a good reason to replace it with a simple concluding slide.

\section{CONCLUSION: AN IMMINENT DEATH FOR "DEATH-BY-POWERPOINT?"}

Our advice leads to visual presentations that are simpler and more visual, and support rather than distract from a speaker's oral points. These presentations contain far fewer slides than are generally seen at our conferences. Our Veto Players presentation is 10 slides long, and we advise presenters to consider this length a maximum for a 15 -minute presentation.

Some may object that these presentations are too simplistic and minimalist for a meeting of like-minded professionals. They are not. These presentations cover all the bases of a good professional talk, including defining and defending a research problem contextualized in an existing literature, laying out a new theory in broad strokes and understandable terms, and proposing and evaluating empirical tests of that theory. Furthermore, this approach fulfills all these goals in a manner designed to accentuate the enthusiasm and flair of the presenter, not to replace it. That is not bad for 15 minutes.

\section{NOTE}

We thank Skip Lupia, the PS editorial staff, and anonymous reviewers for very helpful suggestions and comments.

\section{RE F E R E N C E S}

Brambor, Thomas, William R Clark, and Matt Golder. 2006. "Understanding Interaction Models: Improving Empirical Analyses." Political Analysis 14 (1): $63-82$.

Bumiller, Elisabeth. 2010. "We Have Met the Enemy and He Is PowerPoint. New York Times, April 27, A1.

Duarte, Nancy. 2008: slide:ology. Sebastapol, CA: O’Reilly Media.

Reynolds, Garr. 2008. Presentation Zen. Berkeley, CA: New Riders Press.

Tsebelis, George. 2002. Veto Players. Cambridge: Cambridge University Press.

Tufte, Edward. 2001. The Visual Display of Quantitative Information. 2nd ed. Cheshire, CT: Graphics Press. 